\title{
Morphometric measurements of cinder cones from digital elevation models of Tolbachik volcanic field, central Kamchatka
}

\author{
Michael Gilichinsky, Dmitry Melnikov, Ivan Melekestsev, Natasha Zaretskaya, and Moshe Inbar
}

\begin{abstract}
The present research examines the measured morphometric values of monogenetic cinder cones in the Tolbachik volcanic field, Kluchevskaya volcanic group, Kamchatka. The cones were measured from digital elevation models (DEMs) derived from satellite data (ASTER, ALOS PALSAR, and SRTM) and from digitized topographic maps. GPS measurements of 85 locations were performed in the field to provide geodetic reference for DEM processing and to assess the accuracy of the DEM. A methodology for morphometric measurements on a DEM is proposed. The morphometric parameters derived from a DEM include the main characteristics that control the rate of degradational evolution of the cone, namely height, width, and slope. The measured morphometric values were compared and accuracy assessment was carried out. Our study analyzes the morphometric values of four recent cinder cones formed during the last basaltic eruption in 1975-1976 and five older cinder cones formed during the last 2000 years. We show that morphometric values obtained from a DEM are affected by the resolution change, and characteristics of the same cinder cone may vary among DEMs of different resolutions. Our results indicate that the morphometry of the cinder cones can be well characterized by a DEM derived from remotely sensed data. The calculated morphometric parameters showed a correlation with the spatial resolution of the DEM and relative age of the cinder cones. All DEMs studied (including coarse-resolution SRTM) were found to provide reliable morphometric parameters, although the calculated values varied as a function of spatial resolution.
\end{abstract}

\begin{abstract}
Résumé. Dans la présente recherche, on examine les valeurs morphométriques mesurées à partir des cônes de scories monogéniques dans le champ volcanique de Tolbachik (groupe volcanique Kluchevskaya, Kamchatka). Les cônes ont été mesurés à partir de modèles numériques d'élévation dérivés de données satellitaires (ASTER, ALOS PALSAR et SRTM) et de cartes topographiques numérisées. Des mesures GPS ont été acquises sur le terrain sur 85 sites à titre de référence géodésique pour le traitement du MNE de même que pour évaluer la précision du MNE. On propose une méthodologie pour dériver des mesures morphométriques d'un MNE. Les paramètres morphométriques dérivés d'un MNE incluent les principales caractéristiques qui contrôlent le taux de dégradation du cône : la hauteur, la largeur et la pente. Les valeurs morphométriques mesurées ont été comparées et une évaluation de la précision a été réalisée. Dans cette étude, on analyse les valeurs morphométriques de quatre cônes de scories récents formés lors de la dernière éruption basaltique en 1975-1976 et de cinq plus anciens formés au cours des 2000 dernières années. On montre que les valeurs morphométriques obtenues d'un MNE sont affectées par le changement de résolution et que les caractéristiques d'un même cône de scories peuvent varier selon les différentes résolutions du MNE. Les résultats démontrent que la morphométrie des cônes de scories peut être caractérisée efficacement à l'aide d'un MNE dérivé des données de télédétection. Les paramètres morphométriques calculés sont corrélés avec la résolution spatiale du MNE et l'âge relatif des cônes de scories. On a pu observer que tous les MNE étudiés (incluant les données SRTM à résolution plus grossière) pouvaient donner des paramètres morphométriques fiables bien que les valeurs calculées variaient en fonction de la résolution spatiale.

[Traduit par la Rédaction]
\end{abstract}

\section{Introduction}

The evolution of landscapes over time is a fundamental aspect of geological and geomorphologic studies. Recent volcanic features like cinder cones offer the opportunity to monitor the processes and development of landscapes. Cinder cones are the simplest and most common volcanic landform in the world. They are one of a few landform types with a distinct and defined initial date of formation and lasting no more than a few million years (a brief spell in the Earth's geological history)

Received 3 November 2009. Accepted 11 May 2010. Published on the Web at http://pubservices.nrc-cnrc.ca/cjrs on 15 December 2010.

M. Gilichinsky. ${ }^{1}$ Department of Forest Resource Management, SLU, SE-901 83 Umeå, Sweden.

D. Melnikov and I. Melekestsev. Institute of Volcanology and Seismology, RAS, 683006 Petropavlovsk-Kamchatsky, Russia.

N. Zaretskaya. Geological Institute, RAS, 119017 Moscow, Russia.

M. Inbar. Department of Geography and Environmental Studies, University of Haifa, Haifa, Israel.

${ }^{1}$ Corresponding author (e-mail: michael.gilichinsky@srh.slu.se). 
before erosion processes flatten them. Most cinder cones are conical structures of ballistically ejected fragments topped by a bowl-shaped crater. These small volcanoes are usually similar in structure and composition and often cluster by the dozen or even the hundreds in volcanic fields or on the flanks of larger volcanoes (Hooper and Sheridan, 1998). Geomorphological studies of cinder cones involve measuring their morphometric characteristics, namely height, diameter, and slope, and the relation between them. Morphometric studies of cinder cones, together with tephrochronology and methods of absolute dating, have proven to be efficient tools for determining the age of cinder cones and for characterizing their morphological evolution (Hooper, 1995; Inbar and Risso, 2001; Parrot, 2007). Wood (1980a) has grouped cinder cones into different age categories and compared and contrasted their morphometric parameters. He showed that the evolution of the erosion of a cone is associated with the length of time the cone has been exposed to degradation processes.

Accurate and detailed elevation data are necessary for analyzing the present state of cinder cone morphometry, and the morphometric parameters calculated from the data are commonly used for producing volcanic models (Davidson and De Silva, 2000; Corazzato and Tibaldi, 2006). The change in morphometric parameters with age of the cinder cone due to erosion was observed by Settle (1979), Wood (1980a; 1980b), Hooper and Sheridan (1998), and others. Hooper (1995) used the height to width $(h / W)$ ratio and maximum slope angle of the cinder cones to determine their relative age. Hopper and Sheridan (1998) developed an approach to simulate the surface processes responsible for the erosion of a typical scoria cone. They showed that a longer period of erosion resulted in the systematic decrease (with increasing age) of cinder cone height, cone $h / W$ ratio, maximal and average slope angles, and crater depth to width ratio. They also confirmed that degradation of cinder cones correlates with the duration of exposure to erosion based on a simulation algorithm applied to the digital elevation models (DEMs) derived from topographic maps of the San Francisco volcanic field in Arizona. Inbar and Risso (2001) analyzed morphometric parameters of a large number of cinder cones in the southern Andes. They presented a relative time classification of the studied volcanic field on the basis of the $h / W$ ratio and average slope. Recently, Pelletier and Cline (2007) validated the precise form of the nonlinear slopedependent transport model on a radiometrically dated cinder cone (Lathrop Wells, Nevada).

The introduction of DEMs as digital representations of surface topography has made precise quantitative estimation of cinder cone characteristics possible. Parrot (2007) presented a method for accurate calculation of various geomorphic parameters from high-resolution DEMs (Chichinautzin Range Volcanic Field, Mexico) to simulate the evolution of a given shape and then to estimate the volume of material removed during erosion.

Remotely sensed stereo imagery acquired from spaceborne sensors provides accurate DEMs and offers the potential of worldwide coverage (Kervyn et al., 2008). Digital elevation data gathered by remote sensing methods are widely used to study the dimensions and shape of volcanic structures (Kervyn et al., 2007). Radar interferometry and optical digital photogrammetry are two leading methods used to derive DEMs from remotely sensed datasets. In addition, the development of synthetic aperture radar (SAR) enables collection of imagery required for DEM extraction regardless of weather conditions or time of day.

Volcano morphometry has recently been studied by means of optical and radar remote sensing (Wiart et al., 2000; Kervyn et al., 2007; 2008). DEMs extracted from different remotely sensed sources usually vary in spatial resolution and are affected by three types of errors, namely gross errors (blunders), systematic errors, and random errors (Thapa and Bossler, 1992). Kervyn et al. (2008) performed a comparative analysis of the accuracy of DEMs provided by the Advanced Spaceborne Thermal Emission and Reflection Radiometer (ASTER) and Shuttle Radar Topography Mission (SRTM), focusing on retrieval of quantitative morphometric data for moderate- and small-sized volcanic features.

SAR interferometry has been applied successfully to estimate subtle crustal deformation by natural causes such as earthquakes (Massonnet et al., 1993; Sandwell et al., 2000) and volcanoes (Massonnet et al., 1995; Jonsson et al., 1999; Amelung et al., 2000). The feasibility of using SAR interferometry for monitoring volcano activity has been recently established (Beauducel et al., 2000; Fernández et al., 2002; Lagios et al., 2005). The Advanced Land Observation Satellite (ALOS), which carries a phased array type L-band synthetic aperture radar (PALSAR), was used recently for assessing crustal deformation caused by earthquakes in Western Australia (Ge et al., 2009).

Morphometric parameters can be measured from topographic maps as well as DEMs derived from remotely sensed data. However, the accuracy of the elevation data must be assessed before the morphometric parameters are calculated. Error in elevation data is widely recognized to comprise mainly two components: (i) horizontal error often referred to as positional accuracy, and (ii) vertical error or accuracy (Nikolakopoulos et al., 2006). The horizontal and vertical errors usually cannot be separated: incorrect elevation could appear at the correct location, or the error may be due to a correct elevation in the wrong location.

The spatial resolution of a DEM controls the precision and accuracy of height and slope estimates (Guth, 2006). Kervyn et al. (2008) studied the effect of DEM resolution on the quantitative characterization of volcanic structures using a simulated cinder cone. In their work, the average size and shape of a typical cinder cone introduced by Wood (1980a) was used. Cone base elevation was measured as the average of the highest and lowest basal elevations. Using simulated DEM resolutions of 1, 10, 30, and 90 m, Kervyn et al. illustrated that for quantitative data retrieval from coarser DEM resolutions the consequences are overestimation of horizontal estimates and underestimation of vertical 
estimates. They concluded that the intensity of these effects depends on the size of a volcano relative to DEM resolution, the slope of the volcano, and the sharpness of breaks in slope. Kervyn et al. (2007) showed that identification of small-scale volcanic features (e.g., cinder cones) is hindered when the DEM spatial resolution is coarser than one third of the typical feature size.

Despite much scientific effort invested in different aspects of the eruptions in Kamchatka, no morphometric study based on remote sensing methods has been carried out on the cinder cones. The objective of this study is to analyze calculated morphometric parameters, derived from different DEMs of recent cinder cones formed by an eruption that occurred in 1975-1976, and of older cones formed during the last 2000 years in the Tolbachik volcanic field of the Kluchevskaya volcanic group. These parameters include the main characteristics controlling the rate of degradational evolution of the cone: height, width, height to width ratio, and slope. The morphometric parameters were calculated from DEMs derived from satellite data (ASTER, SRTM, and ALOS PALSAR) and digitized topographic maps. The accuracy of the studied DEMs was assessed by a field global positioning system (GPS) survey, and the consistency of calculated morphometric parameters derived from different DEMs was verified. The effect of DEM resolution on morphometric measurements was also evaluated, and we classified the resulting morphometric parameters of the cinder cones based on the two age groups to help analyze the potential of morphometry for relative dating.

\section{Regional setting}

The Tolbachik volcanic field located in the southwest part of the Kluchevskaya volcanic group is one of the youngest volcanic landforms on the Kamchatka Peninsula (Figure 1). It comprises an inclined lava plane with a total surface area of $875 \mathrm{~km}^{2}$, formed by numerous eruptions of many cinder and lava cones and fewer fissure eruptions. The volcanic centers are related to the $70 \mathrm{~km}$ long Tolbachik regional cinder cone zone and were formed by about 60 volcanic episodes during the Holocene period (i.e., the last 10-11 thousand years) (Fedotov et al., 1984).

Our study is focused on four young cinder cones that formed during the Great Fissure Tolbachik Eruption (GFTE) of 19751976, the most recent episode of Tolbachik volcanic activity, and five older cones that formed during the last 2000 years (Figure 2a; Table 1). The closeness of recent and older cones in the Tolbachik volcanic field facilitated the field GPS measurements (Figures $\mathbf{2 b}, \mathbf{3}$ ). The relative height of all studied

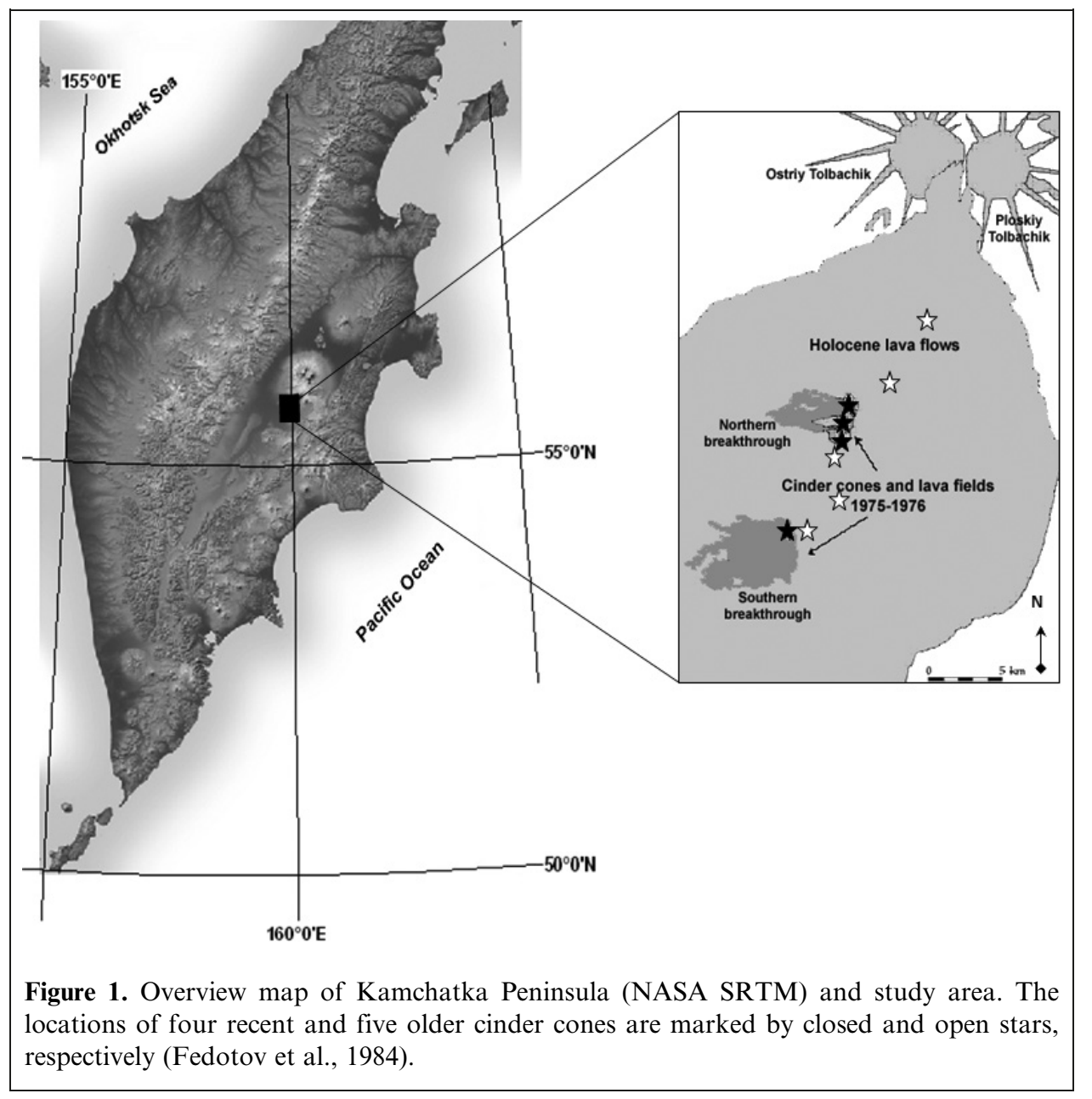




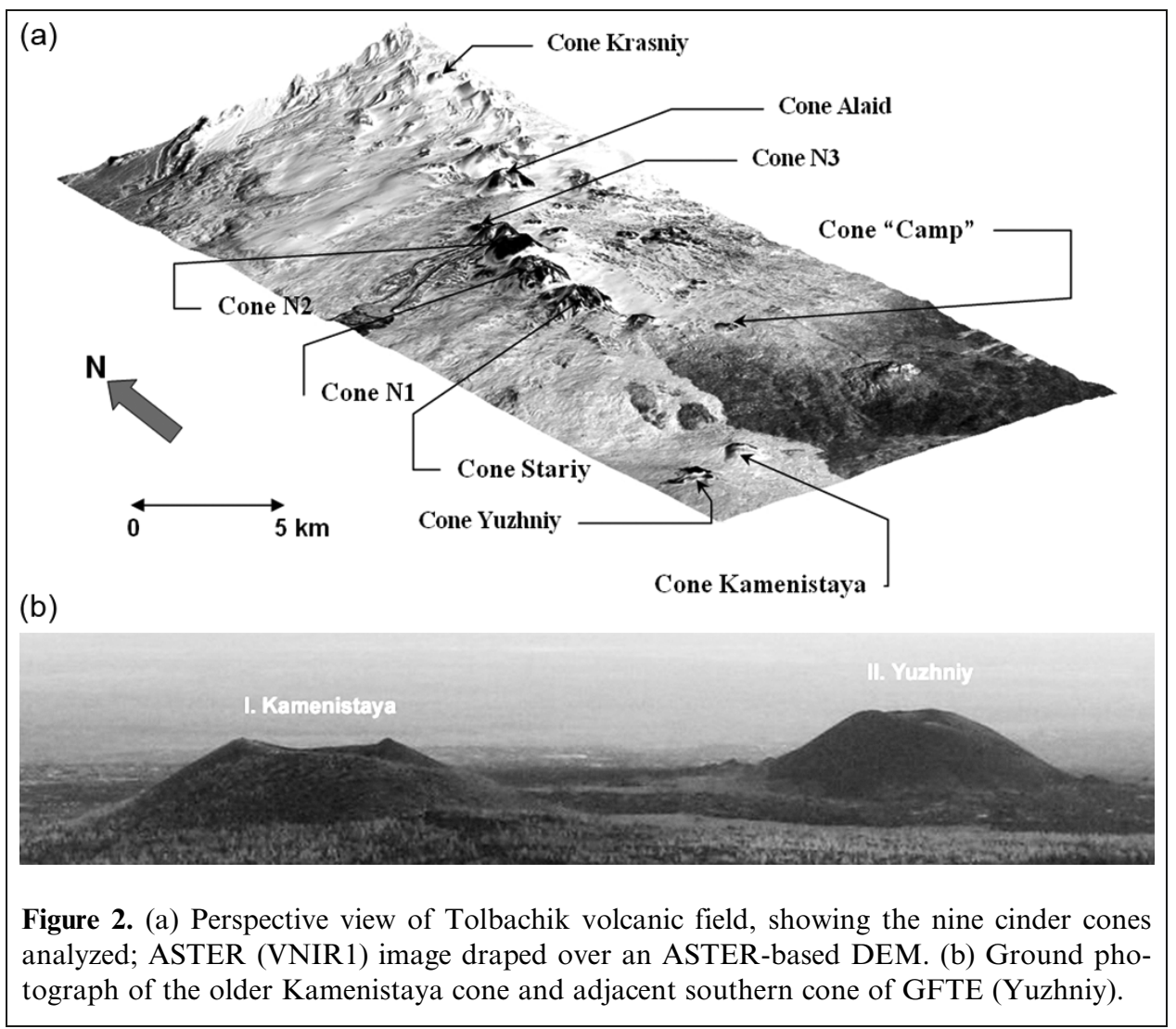

cones (except "Camp") is more than $100 \mathrm{~m}$, and they stand out boldly in the surrounding landscape. Cinder cones formed earlier (10-11 thousand years ago) are far smaller in size and volume, and their surface morphology is notably different.

The 1975-1976 eruption vents were located along a fissure about $28 \mathrm{~km}$ in length. The eruption started from weak explosions from the summit crater of the Plosky Tolbachik volcano. The northern cones were formed approximately $18 \mathrm{~km}$ southwest of Plosky Tolbachik. This eruption produced approximately $0.7 \mathrm{~km}^{3}$ of airborne tephra, which covered an area of approximately $400 \mathrm{~km}^{2}$. After the termination of the activity of the northern cones in September 1975, a new effusive eruption began approximately $10 \mathrm{~km}$ south-southwest of the latter and lasted until December 1976. The eruption formed a single southern cone (Yuzhniy), a large lava field, and a small amount of volcanic cinder. Total volume of the products erupted from Yuzhniy is estimated at approximately $1 \mathrm{~km}^{3}$ (Fedotov et al., 1984).

Table 1. Descriptive characteristics of the nine cinder cones studied.

\begin{tabular}{lllll}
\hline Cinder cone & Code & Age (AD) & Height $(\mathrm{m})^{a}$ & Volume $\left(\mathrm{km}^{3}\right)^{b}$ \\
\hline Recent cones & & & & \\
N1 & CN1 & 1975 & 295 & 0.13 \\
N2 & CN2 & 1975 & 273 & 0.10 \\
N3 & CN3 & 1975 & 108 & 0.02 \\
Yuzhniy & YZN & $1975-1976$ & 105 & 0.02 \\
Older cones & & & & \\
Krasniyc & KRS & 1740 & 110 & 0.10 \\
Alaid & ALD & $1000-1100$ & 220 & 0.12 \\
"Stariy"d & STR & $200-500$ & 180 & 0.12 \\
"Camp"c & CMP & $0-500$ & 75 & 0.01 \\
Kamenistaya $^{c}$ & KMN & $500-1000$ & 115 & 0.02 \\
\hline
\end{tabular}

\footnotetext{
${ }^{a}$ The heights of recent cones were estimated from a DEM based on a fallout cinder map (Budnikov et al., 1983), and those of older cones were measured from a DEM based on a $1: 25000$ scale topographic map.

${ }^{b}$ Volume for cinder cones was obtained from a DEM based on a 1:25000 scale topographic map.

${ }^{c}$ Dating after Fedotov et al. (1984).

${ }^{d}$ Dating after Braitseva et al. (1995).
} 


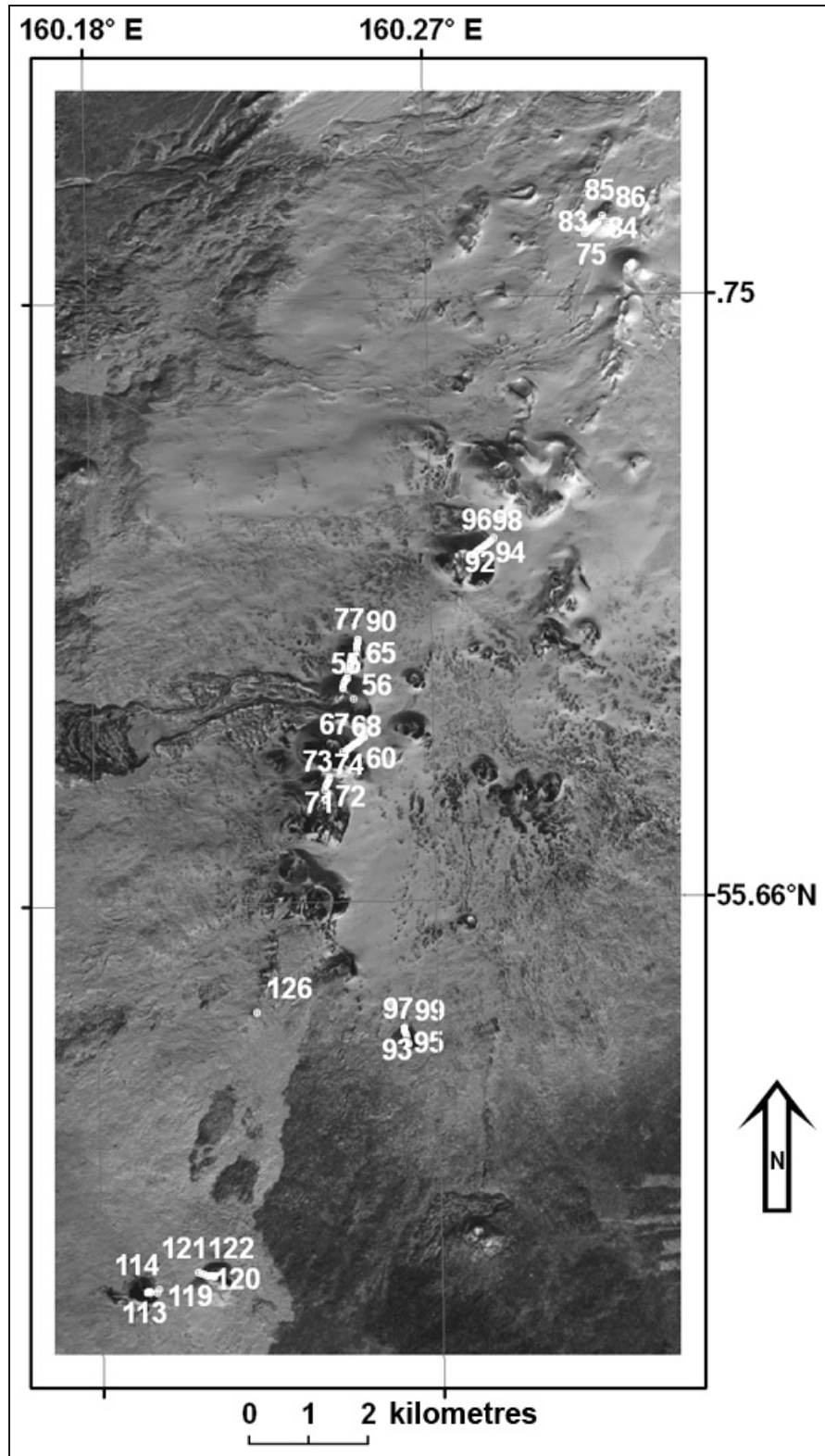

Figure 3. ASTER image (VNIR1) of study area of Tolbachik volcano field showing the locations of some of the 85 field GPS measurements of planar coordinates and elevation.

One of most important characteristics of the study area is the almost total lack of vegetation cover (as a result of cinder fallout during the GFTE), which allows for a more accurate acquisition of surface elevation from remotely sensed data. Due to persistent cloud cover, one of the major problems with the use of optical remotely sensed data was the acquisition of cloudless scenes, required for stereo analysis. The nonuniform occurrence of winter snow cover, which varies from $0 \mathrm{~m}$ on the windy slopes to several metres in the hollows (Abramov et al., 2008), may flatten the DEM and affect the accuracy of morphometric measurements, and therefore only summer images were used for producing a DEM.

\section{Morphometric measurements}

Cone height $(h)$, cone width $(W)$, height to width ratio $(h / W)$, and slope angle calculated from topographic maps are the main morphometric parameters used for determining the rate of cone degradation as a function of its exposure to erosion (Wood, 1980a; 1980b). The standard definition of these parameters is based on measurements derived from topographic maps. In Hooper and Sheridan (1998), cone width is calculated as the average of the maximum and minimum basal diameters for each cone, and cone height is defined as the difference between average basal elevation and maximum crater rim or summit elevation. The $h / W$ ratio reflects the erosive process on the cone and decreases with age as material is removed from the crest of the cone to the cone base (Inbar and Risso, 2001). Hooper and Sheridan presented a progressive decrease in $h / W$ and slope with an increase in age of the cone. They estimated a mean $h / W$ ratio of $0.178 \pm 0.041$ and a mean average slope angle of $26.4 \pm 7.38^{\circ}$ for 12 Holocene cinder cones in the San Francisco volcanic field. Cone slope is obtained by calculating the value of the angle on the triangle outlined by the height and width of the cone (Dóniz et al., 2008).

Additional morphometric parameters measured from the topographic maps, such as cone volume (Hasenaka and Carmichael, 1985), crater depth, and crater width (Porter, 1972; Hooper and Sheridan, 1998), were used as indicators of changing morphology with time and for quantitative characterization of cinder cones.

The DEMs allow definition of morphometric parameters as variables of a continuous topographic surface. In recent studies, DEM-based definitions of main morphometric parameters have been proposed that differ from those for topographic maps (Parrot, 2007; Favalli et al, 2009).

In this study we acquired DEMs from different remotely sensed sources and used the detailed hill-shaded image in combination with a derivative slope image to delineate the outlines of each cinder cone. The morphometric parameters were then calculated by means of an ad hoc developed IDL program. Besides the standard morphometric parameters discussed previously, we calculated the volume of the cinder cones. Recently, traditional handmade cross-sectioning methods for volume estimations on contour maps have been replaced by DEM-based calculations. The volume of a cone cannot be obtained directly from topographic maps. As a solution to this, we have generated DEMs from the contour maps at the scale $1: 25000$ for volume calculations. This allows for the definition of cone volume using the Delaunay triangulation of DEM pixels and calculation of cubic area within the cone basal outline in ArcGIS 9.2 (Table 1).

\section{Cone slope}

The elevation pattern of a cinder cone is well represented on a DEM, allowing for the direct calculation of the main morphometric parameters, including slope (e.g., Mouginis-Mark et al., 1996; Wright et al., 2006). Slope values, calculated as the 
horizontal derivative of elevation change, generally decrease with increasing grid spacing in a DEM (Guth, 2006). A decrease in the spatial resolution of a DEM affects the apparent cone morphology in the vicinity of breaks in slope due to data interpolation between increasingly widely spaced data points (Kervyn et al., 2008). We used slope models in combination with the respective DEMs to calculate the morphometric parameters of each cinder cone. The slope values were calculated in degrees using the ENVI 4.6 topographic modeling procedure for every pixel in the DEM.

Definition of the base of a cinder cone allows for the separation of each feature from its topographic background. In our study the base (e2) of the cinder cone was allocated by the lowest elevation isoline (e1), with an average of slope pixels of more than $5^{\circ}$ (Figure 4a). The basal plane elevation was estimated as the average elevation value of all DEM pixels located along the basal outline. We then calculated the slope of the cinder cone as the average of pixel slope values situated along the steepest profile $(S)$ with the greatest elevation difference (cone height, $h$ ) between the highest cone point and the basal outline on the shortest horizontal distance $L$ (Figure $\mathbf{4 b}$ ).

\section{Cone height and width}

The lowest elevation isoline (e1) was fitted to an ellipse (e2) to facilitate the width measurements (Figure 4a), and then cone width $(W)$ was calculated as the average of the maximum $\left(D_{\max }\right)$ and minimum $\left(D_{\min }\right)$ axes of this ellipse (Figure 4b). The problem in the calculation of the cone height in the case of a steeply dipping basal plane has been described by Favalli et al (2009). However, the shallow-dipping plane characterizing the study area (less than $5^{\circ}$ ) allows for modeling the basal plane of the cone as a flat surface. Based on this and the previous calculations of cone width and height, we calculated $h / W$ according to Wood (1980a).

\section{Data}

The issue of the spatial resolution of a DEM is crucial for quantitative characterization of geomorphologic structures. In our study we used field GPS measurements, DEMs derived from remotely sensed data of various resolutions, and digitized topographic maps for calculating morphometric parameters of the cinder cones in the Tolbachik volcanic field.

\section{Field GPS measurements}

During fieldwork conducted in August 2007 on the Tolbachik volcanic field, GPS measurements were acquired on nine cinder cones located along the main sub-meridian fault. The cones lie at various altitudes $(350-1500 \mathrm{~m}$ above sea level (asl)), and the distance between the outermost cones of this group, namely the south fissure and the Krasny cone (KRS) on the north, is $20 \mathrm{~km}$ (Figure 2a). The elevation measurements were obtained as World Geodetic System 1984 (WGS 84) ellipsoid heights by a Fujitsu-Siemens pocket LOOX

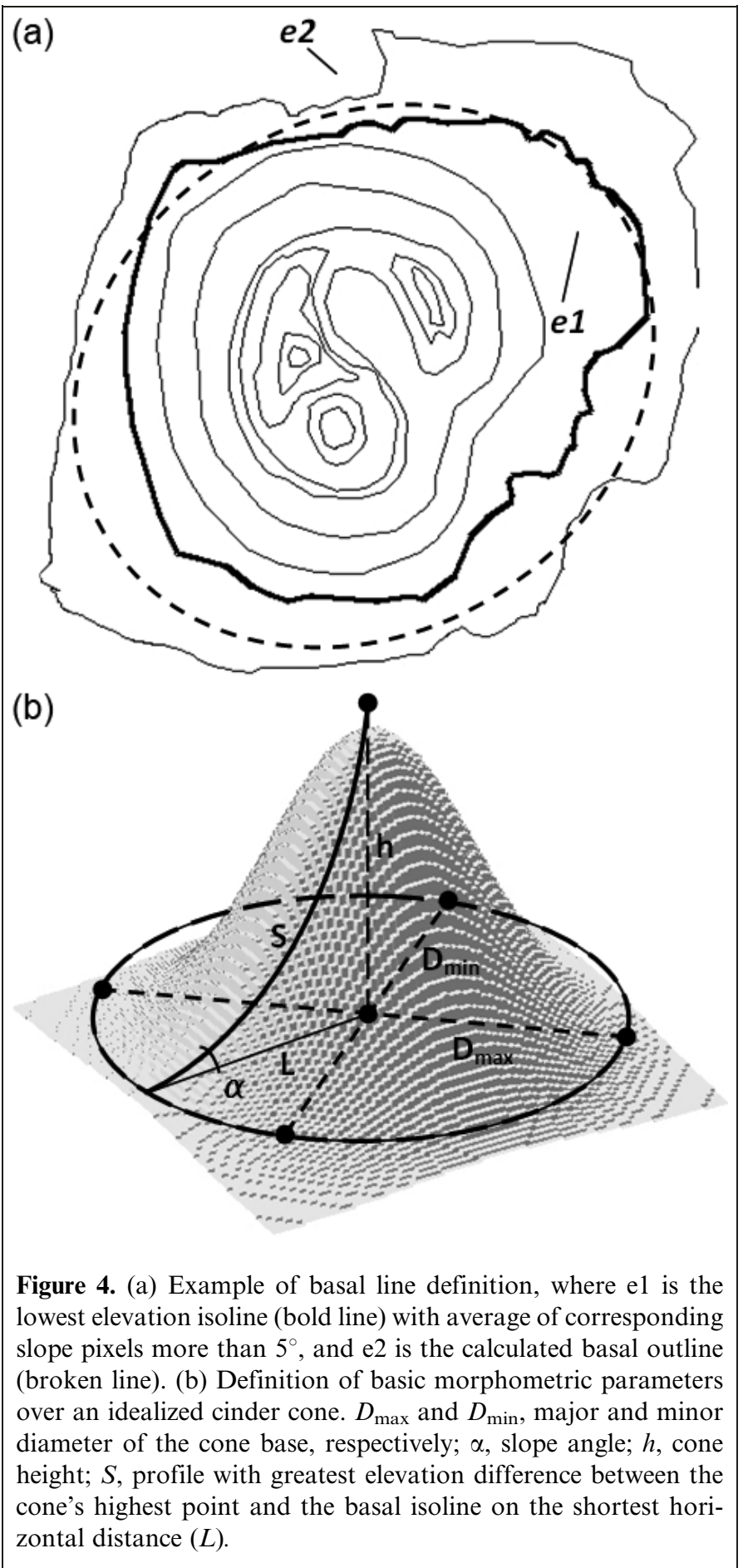

N560 (Sirf III GPS chipset). This hand-held GPS device provides a horizontal accuracy of about $3 \mathrm{~m}$, and its error in elevation can be as high as 7-9 $\mathrm{m}$. In total we collected GPS data at 85 locations within the study area, including 73 measurements of randomly oriented elevation profiles of the nine cinder cones (Figure 3). The ground control points (GCPs) were corrected to geoid heights of Earth Gravitational Model 1996 (EGM96) and used in DEM generation, employing the DEM Extraction Module (ENVI 4.6). The GPS measurements were also used to evaluate the accuracy 
of the DEMs generated from the remotely sensed data and topographic contour map.

\section{ASTER}

ASTER (launched in December 1999) is a medium to high spatial resolution, multispectral imaging system that collects data from the visible to thermal infrared portion of the electromagnetic spectrum (EM). Volcano hazard monitoring and geological and soil mapping are specific applications for which ASTER was developed (Pieri and Abrams, 2004). An ASTER scene, covering $61.5 \mathrm{~km} \times 63.0 \mathrm{~km}$, comprises data from 14 spectral bands divided into three portions of the EM spectrum: visible near infrared (VNIR), short-wave infrared (SWIR), and thermal infrared (TIR). The highresolution VNIR optical instrument (15 m spatial resolution) records spectral reflection from the visible to near-infrared $(0.52-0.86 \mu \mathrm{m})$ portion of the EM spectrum. The VNIR sensor has two near-infrared bands with similar wavelengths, namely $3 \mathrm{n}$ (nadir looking) and $3 \mathrm{~b}$ (backward looking) with an angle of $27.6^{\circ}$. The purpose of the addition of band $3 \mathrm{~b}$ is to obtain stereoscopic images for generating and processing DEMs (Hirano et al., 2003).

In general, the accuracy of DEMs derived from ASTER data depends on the availability, spatial distribution, and accuracy of GCPs and image contrast (Kervyn et al., 2008). Several studies have shown that the vertical accuracy of an ASTER DEM approaches $25 \mathrm{~m}$, but this can improve to $9-11 \mathrm{~m}$ in areas with less vegetation cover (Goncalves and Oliveira, 2004). Kamp et al. (2003) reported that an ASTER DEM has optimal accuracy for medium-scale mapping (1:100 000 and $1: 50000$ ). Hirano et al. (2003) found that the root mean square error (RMSE) in ASTER DEM elevations ranges from \pm 7 to $\pm 15 \mathrm{~m}$, depending on the availability and quality of GCPs and image quality.

A cloud-free ASTER scene of the study area acquired in August 2004 was selected. Derivation of a DEM from ASTER data began with image orthorectification. The nadir image VNIR3N (left stereo image) and backward-looking VNIR3B (right stereo image) were orthorectified by means of rational polynomial coefficients (RPCs) based on sensor geometry, information derived from the metadata and product documentation of each ASTER scene. The ASTER DEM was generated using a photogrammetric solution available in the ENVI DEM Extraction Module. The DEM extraction procedure was based on automatic recognition of textural patterns common in the two stereo ASTER images and matching of the corresponding pixels. The absolute orientation of a DEM generated from an ASTER stereo pair is obtained by locating a minimum of six GCPs on both images. The availability of 40 GCPs precisely located in the field and on the ASTER stereo pair allowed for good absolute orientation of the generated DEM. A number of experimental DEMs were generated by varying the DEM spatial resolution and matching interval of the two epipolar image templates (left and right images of the stereo pair). A compromise is required between the spatial resolution necessary for the matching process and the increasing proportion of artifacts (pixels with abnormal high or low elevation values). Optimal results were obtained by a matching interval of three pixels and a spatial resolution of $30 \mathrm{~m}$. Holes in the DEM were filled by automated interpolation and then smoothed by a $3 \times 3$ low-pass filter to reduce the effect of possible artifacts.

\section{SRTM}

The National Aeronautics and Space Administration (NASA) SRTM provided digital elevation data for over $80 \%$ of the globe during the Endeavour mission (February 2000 ) using both C-band (5.6 cm wavelength) and X-band $(3 \mathrm{~cm})$ radar. These data were collected by a technique known as interferometry, which allows for the extraction of elevation data from imagery acquired by dual radar antennas. Unlike ALOS data, SRTM data are free and are provided in a "ready-to-use" format that does not require preprocessing operations. SRTM data are grouped into individual raster tiles, each covering $1^{\circ}$ by $1^{\circ}$ in latitude and longitude. Sample spacing for individual data points is 1, 3 , or 30 arc-seconds, referred to as SRTM1, SRTM3, and SRTM30, respectively.

The $90 \mathrm{~m}$ dataset (SRTM3) is produced by subsampling the 30 m DEM (SRTM1), whereas only the central pixel of any $3 \times 3$ pixel matrix of the original data remains in the subsampled DEM (Kervyn et al., 2007). Alternatively, averaged data for each $3 \times 3$ pixel matrix are also available (Gesch et al., 2006). SRTM-based elevation data were validated on continental scales by comparison with reserved ground control (Farr et al, 2007) yielding an absolute vertical accuracy for Eurasia of about $9 \mathrm{~m}$, but accuracies decrease to 12-13 m in steep terrain (Rodríguez et al., 2006; Farr et al., 2007). Kervyn et al. (2008) showed that a spatial resolution of $90 \mathrm{~m}$ limits the vertical accuracy of topographic features, thus reducing the usefulness of SRTM data. Nevertheless, the SRTM3 is one of the best available topographic datasets for Kamchatka. Guth (2006) compared the SRTM with the cartographically derived National Elevation Dataset (NED) at different simulated scales and showed that basic topographic parameters derived from these two datasets (i.e., average elevation) are highly correlated. Compared with NED, the true resolution of SRTM1 is actually about 2 arc-seconds, whereas the SRTM3 data closely resemble 3 arc-seconds NED. SRTM is generally noisy in flat areas, which increases the average slope, whereas in high-relief areas it over-smoothes the topography and lowers average slopes (Guth, 2006). Comparison of ASTER and SRTM DEM data in the complex physiographic landscape of Crete indicated close correlation of calculated elevation (Nikolakopoulos et al., 2006).

SRTM3 elevation data for the study area were obtained from the NASA - US Geological Survey (USGS) ftp-server. For Kamchatka, SRTM3 data are available as DEMs with a 3 arc-second ( $\sim 90 \mathrm{~m})$ spatial resolution. The SRTM data (orthometric heights) used in this study were projected using 
the WGS 84 horizontal datum to a Universal Transverse Mercator (UTM) projection (UTM zone $57 \mathrm{~N}$ ). A nearest neighborhood resampling method was used to preserve $90 \mathrm{~m}$ pixel size.

\section{ALOS}

ALOS is a Japanese satellite launched on 24 January 2006 and carrying an L-band SAR sensor (PALSAR). The maximum ground resolution of ALOS PALSAR is $7 \mathrm{~m}$, representing one of the highest spatial resolutions among current SAR sensors. Interferometric ALOS PALSAR data can be analyzed every 46 days due to the ALOS orbit revisit time. The fine beam is the ALOS PALSAR main acquisition mode and is primarily used for detailed regional observations and repeat-pass interferometry. Data in this mode can be acquired as single polarization (FBS) or dual polarization (FBD).

ALOS PALSAR derived elevation data have not yet been evaluated for morphometric measurements of small-scale volcanic features, although recent studies have shown that ALOS DEM data are useful for precise measurements of various surface deformations. Matsuoka (2006) demonstrated the ability of ALOS to monitor areas damaged by earthquake activity (in Yogyakarta, central Java, Indonesia) by comparing the correlation coefficient of a pre-event image pair with that of an image pair spanning the earthquake. The estimated damage distribution closely matched damage assessment derived from high-resolution satellite and field surveys. Joyce et al. (2009) used the ALOS PALSAR data to extract the path of a lahar (pyroclastic mudflow) by calculation of a coherence map from images acquired 2 months before and 9 months after the lahar event. Cheng (2007) tested the possibility of generating high-accuracy orthoimages and mosaics derived from PALSAR data without GCPs, and the results showed RMS errors of one pixel were consistently achieved. The DEM generated from ALOS PALSAR data was used by $\mathrm{Yu}$ et al. (2009) to exploit the information contained in the area of overlap between DEMs of different scales to reduce the total DEM data size.

In our study, ALOS PALSAR data in the form of three interferometric SAR image pairs were acquired in FBD mode. The processing of interferometric pair composition and DEM extraction was carried out through the following main steps using the SARscape Interferometry Module of ENVI: (i) geometric registration of the interferometric SAR image pairs; (ii) generation of an interferogram to reveal information about elevation and measure displacement of objects between the two image acquisitions, where an interferogram is obtained by the interference pattern generated from the phase information contained in two SAR images of the same terrain; (iii) separation of phase components by the phase unwrapping technique, which permits retrieval of the unwrapped phase from the wrapped phase; (iv) determination of the relationship between the heights and the phase differences and conversion of phase values to elevation (generation of a DEM); and $(v)$ generation of a DEM at a spatial resolution of $14 \mathrm{~m}$.

\section{Map-based DEM}

The mapping of erupted material from four cinder cones was carried out during the GFTE, and the entire Tolbachik volcanic field was topographically surveyed at a scale of $1: 25000$ in 1976-1980 (Budnikov et al., 1983). The availability of these data allowed preparation of a detailed cartographically derived (map-based) DEM by digitization of fallout cinder maps and topographic maps (Figure 5). A map-based DEM was compiled from the fallout cinder isopachs maps and the topographic maps of the Tolbachik volcanic field at a scale of $1: 25000$. The DEM was generated from $5 \mathrm{~m}$ contour lines and spot heights that were digitized manually, followed by an elevation assignment to each digitized feature. Triangular irregular networks (TINs) were created from the digitized data and transformed into a raster

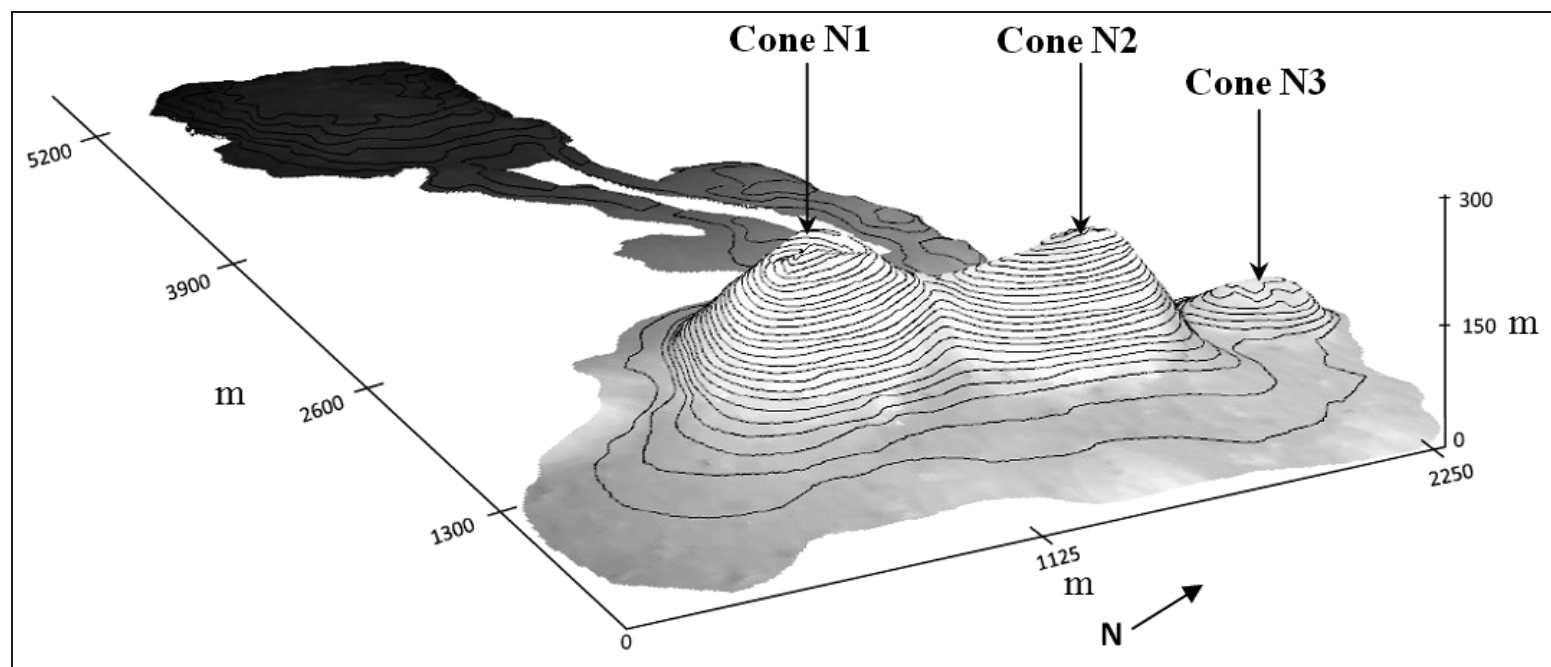

Figure 5. Three-dimensional view of digitized elevation contours derived from a fallout cinder map of three recent cones of the northern breakthrough (locations shown in Figure 2a). 
Table 2. General statistics of DEMs and elevation errors.

\begin{tabular}{lclll}
\hline Source & $\begin{array}{c}\text { Elevation } \\
\text { range }(\mathrm{m})\end{array}$ & $\begin{array}{l}\text { Mean } \\
\text { elevation }(\mathrm{m})\end{array}$ & $\begin{array}{l}\text { Standard } \\
\text { deviation }(\mathrm{m})\end{array}$ & RMSE (m) \\
\hline ASTER & $413-1694$ & 1015.6 & 345.2 & $21.2(2.1 \%)$ \\
SRTM & $399-1644$ & 993.1 & 339.8 & $32.8(1.6 \%)$ \\
ALOS & $414-1655$ & 1019.1 & 338.2 & $19.3(1.8 \%)$ \\
\hline
\end{tabular}

image, creating a DEM at a resolution of $10 \mathrm{~m}$ using the Spatial Analyst tool (ArcGIS 9.2).

\section{Results}

\section{DEM accuracy}

The assessment of DEM accuracy is an important preliminary stage before calculating morphometric parameters. We have calculated overall and local (per cinder cone) DEM accuracy characteristics to facilitate the comparison between DEMs of different spatial resolutions. Overall elevation statistics were calculated from the ASTER DEM, SRTM, and ALOS DEM within the study area and compared with the reference map-based DEM. The elevation values from 256 control points selected randomly in the map-based DEM were compared with the elevation values of the respective DEMs. Due to unavoidable misplacement between assessed and reference DEMs, the elevation value at each control point in the reference DEM was compared with the elevation value of the pixel with the nearest planimetric coordinates in the assessed DEM grid. The overall elevation accuracy of each DEM was calculated as the square root of the average of the set of squared elevation differences (root mean square error, RMSE) between control points and corresponding DEM locations. A summary of DEM overall accuracy is presented in Table 2.

The local accuracy of the DEM provides an indication of error distribution in a particular location. To assess the DEM local accuracy (vertical and horizontal) for each cinder cone, we used GCPs collected in the field (Table 3). The vertical (elevation) accuracy was estimated by RMSE of all the observations of vertical errors in the cone. Since horizontal (spatial) error is distributed in two dimensions, the horizontal accuracy was estimated by RMSE of the Euclidean distance between each GCP measured in the field and the center of the pixel with the same planimetric coordinates in the DEM. The resulting errors might be attributed to the remotely sensed elevation data and the accuracy of GPS measurements.

Local accuracy of each DEM is proportional to the spatial resolution of the DEM: coarser spatial resolution results in greater errors in elevation, with the SRTM DEM showing the highest error. The comparison of accuracy characteristics of the ALOS DEM with those of the ASTER DEM or SRTM has not been reported in the literature. However, the accuracy assessment of the ASTER DEM and SRTM agrees with the results of previous studies (Eckert et al., 2005; Kervyn et al., 2007; 2008).

\section{Morphometric parameters}

Morphometric parameters of cone height, slope, and basal width were calculated from the DEMs derived from remotely sensed data and from the map-based DEM (Table 4). The spatial resolution of each DEM directly affects the accuracy of elevation estimates as discussed in the previous section. In general, as the pixel size of the DEM is increased, a single elevation value represents a larger area. Thus, this will also affect the calculated morphometric values. A comparison of relative coarse-resolution DEMs (SRTM) with high-resolution DEMs (ASTER, ALOS, and map-based) presented in Table 4 shows underestimation of smaller height values and overestimation of larger width values of the cinder cones. In addition, the slope values tend to decrease in all studied cones as the DEM resolution becomes coarser.

All the DEMs were pairwise compared to examine the effect of different resolutions on cone height and width estimates

Table 3. Assessment of vertical and horizontal RMSE based on ground control points (GCPs).

\begin{tabular}{|c|c|c|c|c|c|c|c|c|c|}
\hline \multirow[b]{2}{*}{$\begin{array}{l}\text { Cinder } \\
\text { cone }\end{array}$} & \multirow[b]{2}{*}{$\begin{array}{l}\text { No. } \\
\text { of GCPs }\end{array}$} & \multicolumn{2}{|c|}{ ASTER DEM } & \multicolumn{2}{|l|}{ SRTM } & \multicolumn{2}{|c|}{ ALOS DEM } & \multicolumn{2}{|c|}{ Map-based DEM } \\
\hline & & $\begin{array}{l}\text { Vertical } \\
(\mathrm{m})\end{array}$ & $\begin{array}{l}\text { Horizontal } \\
(\mathrm{m})\end{array}$ & $\begin{array}{l}\text { Vertical } \\
(\mathrm{m})\end{array}$ & $\begin{array}{l}\text { Horizontal } \\
\text { (m) }\end{array}$ & $\begin{array}{l}\text { Vertical } \\
(\mathrm{m})\end{array}$ & $\begin{array}{l}\text { Horizontal } \\
\text { (m) }\end{array}$ & $\begin{array}{l}\text { Vertical } \\
(\mathrm{m})\end{array}$ & $\begin{array}{l}\text { Horizontal } \\
(\mathrm{m})\end{array}$ \\
\hline CN1 & 10 & 9.9 & 14.6 & 15.1 & 31.7 & 6.3 & 9.1 & 8.7 & 10.1 \\
\hline $\mathrm{CN} 2$ & 8 & 9.6 & 14.8 & 14.6 & 38.4 & 8.1 & 11.4 & 7.4 & 8.2 \\
\hline $\mathrm{CN} 3$ & 9 & 8.4 & 13.1 & 13.8 & 35.6 & 7.1 & 10.2 & 6.4 & 7.4 \\
\hline YZN & 9 & 8.3 & 12.2 & 7.6 & 23.6 & 5.2 & 7.7 & 4.9 & 5.2 \\
\hline KRS & 9 & 15.1 & 23.3 & 10.2 & 33.9 & 10.3 & 15.9 & 7.0 & 7.7 \\
\hline ALD & 7 & 10.6 & 16.9 & 12.0 & 34.4 & 10.8 & 16.1 & 6.1 & 6.9 \\
\hline STR & 7 & 9.0 & 12.9 & 12.5 & 32.1 & 7.1 & 9.8 & 7.9 & 8.8 \\
\hline CMP & 5 & 9.3 & 13.7 & 9.7 & 18.7 & 8.6 & 12.1 & 3.9 & 4.1 \\
\hline KMN & 9 & 4.1 & 6.1 & 9.8 & 19.3 & 4.2 & 5.8 & 4.8 & 5.5 \\
\hline
\end{tabular}


Vol. 36, No. 4, August/août 2010

Table 4. Morphometric parameters measured from DEMs of different sources.

\begin{tabular}{|c|c|c|c|c|c|c|c|c|c|c|c|c|}
\hline \multirow[b]{2}{*}{ Cone } & \multicolumn{3}{|l|}{ ASTER } & \multicolumn{3}{|l|}{ SRTM } & \multicolumn{3}{|l|}{ ALOS } & \multicolumn{3}{|c|}{ Map-based } \\
\hline & $\begin{array}{l}\text { Height } \\
(\mathrm{m})\end{array}$ & $\begin{array}{l}\text { Width } \\
(\mathrm{m})\end{array}$ & $\begin{array}{l}\text { Slope } \\
\left({ }^{\circ}\right)\end{array}$ & $\begin{array}{l}\text { Height } \\
(\mathrm{m})\end{array}$ & $\begin{array}{l}\text { Width } \\
(\mathrm{m})\end{array}$ & $\begin{array}{l}\text { Slope } \\
\left({ }^{\circ}\right)\end{array}$ & $\begin{array}{l}\text { Height } \\
(\mathrm{m})\end{array}$ & $\begin{array}{l}\text { Width } \\
(\mathrm{m})\end{array}$ & $\begin{array}{l}\text { Slope } \\
\left({ }^{\circ}\right)\end{array}$ & $\begin{array}{l}\text { Height } \\
(\mathrm{m})\end{array}$ & $\begin{array}{l}\text { Width } \\
(\mathrm{m})\end{array}$ & $\begin{array}{l}\text { Slope } \\
\left({ }^{\circ}\right)\end{array}$ \\
\hline CN1 & 290 & 1250 & 26.8 & 275 & 1300 & 25.4 & 293 & 1181 & 27.1 & 300 & 1150 & 32.4 \\
\hline $\mathrm{CN} 2$ & 275 & 1100 & 26.2 & 260 & 1200 & 24.6 & 275 & 1073 & 26.4 & 280 & 1050 & 30.9 \\
\hline $\mathrm{CN} 3$ & 110 & 524 & 26.1 & 100 & 556 & 22.1 & 110 & 510 & 26.4 & 110 & 478 & 29.9 \\
\hline YZN & 95 & 452 & 25.0 & 90 & 529 & 21.6 & 102 & 461 & 25.3 & 105 & 477 & 31.4 \\
\hline KRS & 172 & 853 & 24.5 & 159 & 813 & 20.6 & 177 & 872 & 24.7 & 180 & 890 & 28.9 \\
\hline ALD & 210 & 1175 & 24.3 & 205 & 1364 & 20.9 & 210 & 1149 & 24.5 & 220 & 1120 & 27.9 \\
\hline STR & 165 & 1179 & 22.5 & 140 & 1100 & 19.8 & 169 & 1100 & 22.7 & 180 & 1060 & 26.9 \\
\hline CMP & 75 & 555 & 21.1 & 70 & 550 & 19.6 & 75 & 541 & 21.5 & 75 & 540 & 25.4 \\
\hline KMN & 110 & 688 & 19.5 & 100 & 850 & 17.7 & 112 & 660 & 19.7 & 115 & 640 & 24.9 \\
\hline
\end{tabular}

(Figure 6). Despite the resolution differences of the DEMs, the morphometric values show good correlation with the relative age of the cinder cones. Although the calculated morphometric parameters are numerically different, the recent cones are characterized by repeating a pattern of higher slope and $h / W$ values in all the DEMs. For example, four of the recent cones have the highest slope values in all the DEMs; the two cones with the highest slopes (cones N1 and N2) correlate with the highest values of $h / W$ (Figure 7). The calculated height and width of these cones are also the highest of all the DEMs. This suggests
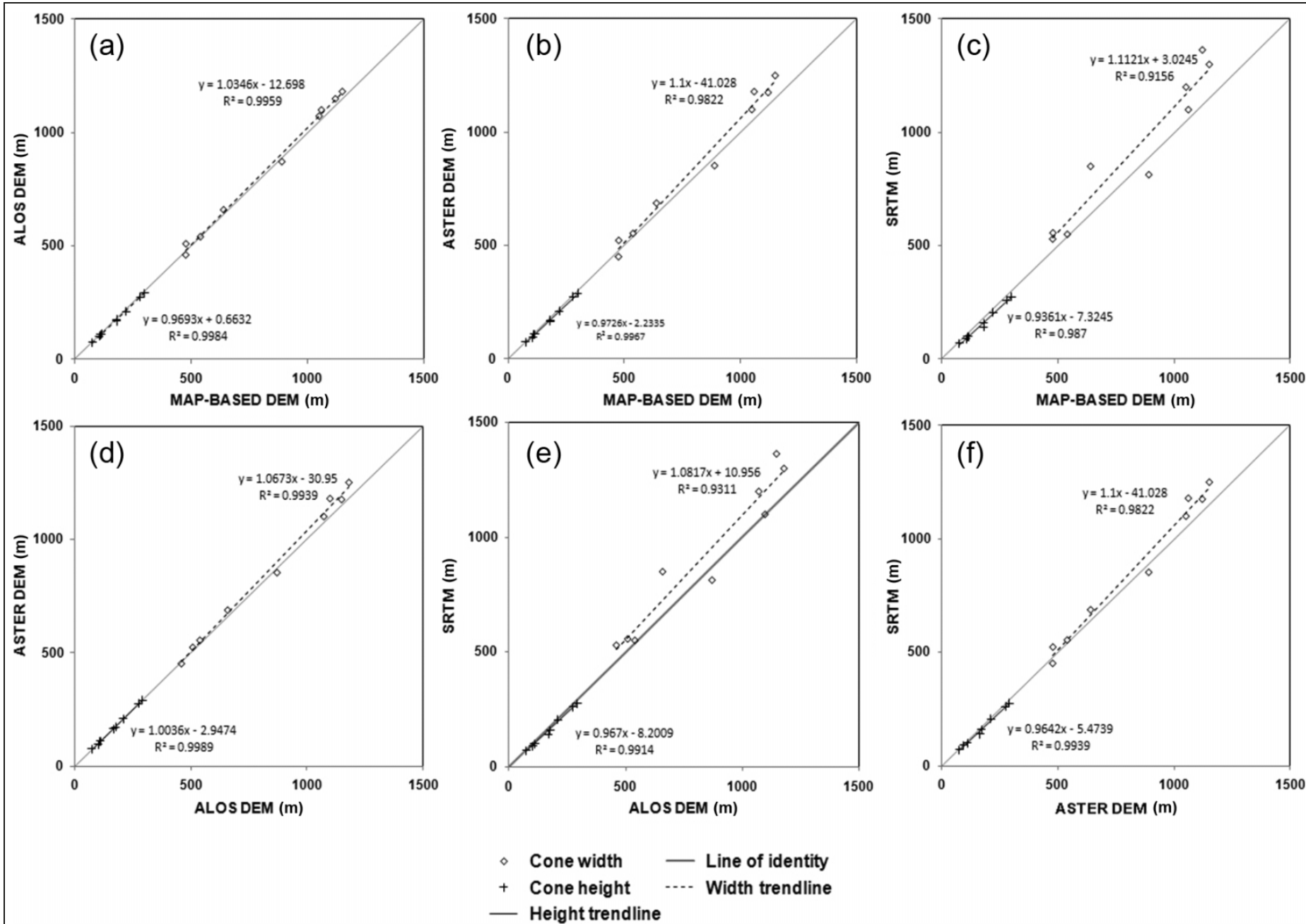

+ Cone height $\quad . .$. Width trendline

- Height trendline

Figure 6. Comparison of height and width estimates obtained from the DEMs for the nine investigated cinder cones: (a) map-based DEM versus ALOS DEM; (b) map-based DEM versus ASTER DEM; (c) map-based DEM versus SRTM; (d) ALOS DEM versus ASTER DEM; (e) ALOS DEM versus SRTM; (f) ASTER DEM versus SRTM. 

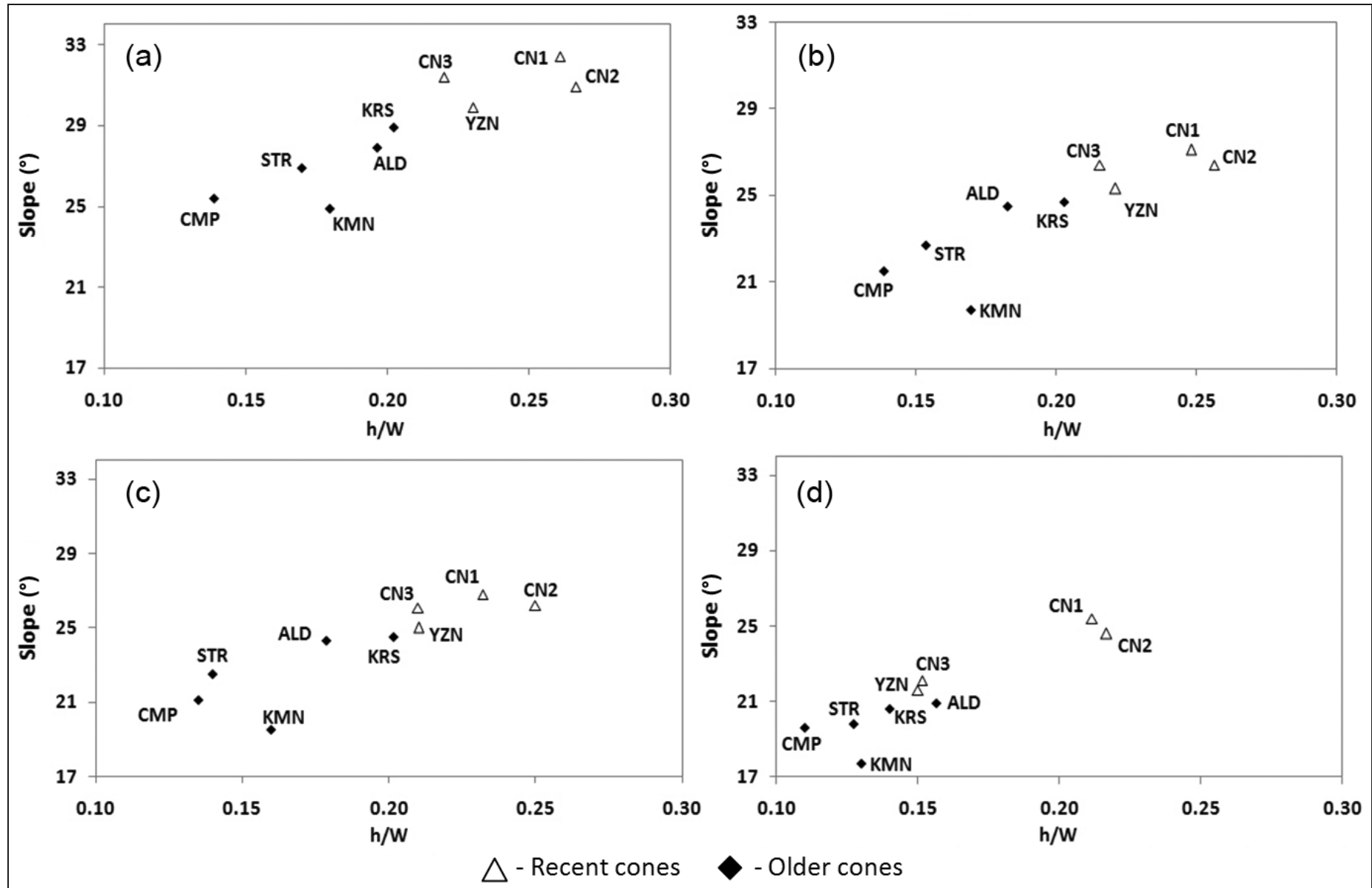

Figure 7. Comparison of cone slope values with the $h / W$ ratio of the nine investigated cinder cones (see Table 1): (a) map-based DEM; (b) ALOS DEM; (c) ASTER DEM; (d) SRTM DEM. Note that the same scale used in the scatterplots allows for the comparison of the relationship between morphometric values measured from different DEMs and relative age.

that elevation averaging (smoothing) caused by a decrease in DEM resolution has a greater effect on the smaller cones than on the larger cones.

Height and basal width were used to calculate $h / W$ and were compared with slope values. The graphic comparison of the slope and $h / W$ values shows consistency in distribution of these parameters in all the DEMs and demonstrates a continuous shift towards smaller values of slope and $h / W$ with a decrease in the DEM spatial resolution (Figure 7). The $h / W$ ratio of the recent cones calculated from the map-based DEM is on average $0.24 \pm 0.02$, and the average slope is $31.1 \pm 1.1^{\circ}$; in older cones the estimated average $h / W$ is $0.18 \pm 0.03$ and the average slope is $26.9 \pm 1.7^{\circ}$. Thus, the map-based DEM, which has the highest spatial resolution, has provided the highest slope and $h / W$ values, whereas the lowest values were obtained from the lowest resolution DEM (SRTM).

\section{Discussion and conclusion}

The objective of our study was to analyze the morphometric parameters of cinder cones calculated from DEMs derived from different data sources in the Tolbachik volcanic field. In this paper we have assessed the DEM accuracy and examined the effect of spatial resolution on calculated morphometric parameters.

The utility of DEMs for accurate topographic mapping of mountainous and volcanic terrain has been recently shown (Kääb, 2005; Stevens et al., 2004; Kervyn et al., 2008; Huggel et al., 2008). However, since ALOS data became available, only a few PALSAR DEM applications have been reported in volcanic regions (e.g., Furuya, 2007; Hu et al., 2009), and they have not been evaluated for morphometric measurements.

The morphometric parameters of cone slope, height, and width were measured from the remotely sensed DEMs and compared with those from a map-based DEM (Table 4). We found that a decrease in DEM resolution directly affected the values of the calculated morphometric parameters for each of the cinder cones. The smoother representation of the surface by coarser resolution DEMs is caused by interpolation of increasingly widely spaced data points in the vicinity of breaks in slope (Wright et al., 2006; Kervyn et al., 2008). This effect was also observed in our study, and of all the elevation models we studied, the SRTM DEM showed the greatest underestimation of elevation values 
and overestimation of cone width compared with those from the map-based DEM (Table 4).

The relationship between cone height and cone width estimates obtained from the different DEMs is illustrated in Figure 6. Comparison of the map-based DEM and SRTM (Figure 6c) clearly shows that the width estimates of four recent cones have been overestimated and height values underestimated. This trend is supported by the observations in other DEM pairs as well. This could greatly alter the slope and height to width $(h / W)$ ratio, especially for smaller cinder cones.

Lower resolution DEMs are inherently less able to represent smaller elevation variations, and as a result calculated slope and $h / W$ values are lower (Figure 7). As expected, the recent cinder cones have provided the highest morphometric values (slope and $h / W$ ) in all the DEMs, regardless of resolution. A coarse-resolution DEM results in lower morphometric values but generally preserves the tendency in correlation between slope and $h / W$ as do high-resolution DEMs (Figure 7). Morphometric parameters calculated from all the DEMs clearly support the concept of relative morphometric dating, as the most recent cinder cones are always associated with the highest slopes and $h / W$ values (Figure 7). However, the straightforward numerical comparison of morphometric values measured from DEMs of different resolution might be erroneous. In such a case, the young cinder cones depicted on a coarse-resolution DEM might result in morphometric values similar to those of older cones calculated from a high-resolution DEM. Thus, morphometric parameters of younger cinder cones measured from a coarse-resolution DEM are underestimated compared with those from a high-resolution DEM. The decrease in DEM resolution affects the morphometric parameters of the cinder cones in a way similar to that of erosion by reducing $h / W$ and slope. We emphasize that, especially on smaller cinder cones, the decrease in DEM resolution alters the calculated morphometric values and consequently the relative age. For example, the recent cone (CN3) in SRTM DEM has been characterized by an $h / W$ value of 0.15 and a slope of $21.5^{\circ}$, which generally correspond to the older cone (STR) in ASTER DEM (Figures 7b, 7d). Thus, the relative age should be obtained by comparing morphometric parameters of cinder cones from DEMs of the same resolution.

From our results, the morphometry of the cinder cones can be well characterized with DEMs derived from remotely sensed data. However, spatial resolution controls the ability of the DEM to represent the local topography of cinder cones. This must be considered if morphometric parameters measured from a coarse-resolution DEM are used for cinder cone classification, estimation of erosion rates, and relative dating.

To our knowledge, this is the first work that has investigated the effect of DEM resolution on quantitative estimation of morphometric values and the effect they have on the relative dating of volcanic cinder cones. A comparison of recent cinder cones with older cinder cones in the study area shows that change in morphometric parameters is not just a function of time. Environmental conditions greatly affect the rate of erosion and thus changes in morphometric values. Very intense erosional processes in central Kamchatka result in measurable morphological change of cinder cones over a geologically short time frame of thousands of years. The morphometric parameters of the recent Tolbachik cinder cones serve as valuable benchmark data for determining erosion rates and future research on the geomorphological evolution of a volcanic landscape.

\section{Acknowledgements}

We thank Bill Morris and Jeff Harris for beneficial suggestions and comments on an earlier version of this paper. We are also grateful to the Institute of Volcanology and Seismology in Petropavlosk-Kamchatsky, Russia, for logistic support of the field study. This work was performed under Israel Ministry of Science and Technology grant 3-3572 and Russian Foundation for Basic Research grant 06-05-72008.

\section{References}

Abramov, A., Gruber, S., and Gilichinsky, D. 2008. Mountain permafrost on active volcanoes: field data and statistical mapping, Klyuchevskaya volcano group, Kamchatka, Russia. Permafrost and Periglacial Processes, Vol. 19, pp. 261-277. doi:10.1002/ppp.622.

Amelung, F., Jonsson, S., Zebker, H.A., and Segall, P. 2000. Widespread uplift and 'trapdoor' faulting on Galapagos volcanoes observed with radar interferometry. Nature (London), Vol. 407, pp. 993-996. doi:10. $1038 / 35039604$.

Beauducel, F., Briole, P., and Froger, J.-L. 2000. Volcano wide fringes in ERS SAR interferograms of Etna: Deformation or tropospheric effect? Journal of Geophysical Research, Vol. 105, No. B7, pp. 402. doi:10.1029/ 2000JB900095.

Braitseva, O., Melekestsev, I., Ponomareva, V., and Sulerzhitsky, L. 1995. Ages of calderas, large explosive craters and active volcanoes in the Kuril-Kamchatka region, Russia. Bulletin of Volcanology, Vol. 57, pp. 383-402.

Budnikov, V.A., Markhinin, Ye.K., and Ovsyannikov, A.A. 1983. The quantity, distribution and petrochemical features of pyroclastics of the great Tolbachik fissure eruption. In The great Tolbachik fissure eruption. Edited by S.A. Fedotov and Ye.K. Markhinin. Cambridge University Press, New York, pp. 41-56.

Cheng, P. 2007. Automated high-accuracy orthorectification and mosaicking of PALSAR data without ground control points. GEO Informatics, Vol. 10, No. 6, pp. 36-38.

Corazzato, C., and Tibaldi, A. 2006. Fracture control on type, morphology and distribution of parasitic volcanic cones: an example from Mt. Etna, Italy. Journal of Volcanology and Geothermal Research, Vol. 158, pp. 177194. doi:10.1016/j.jvolgeores.2006.04.018.

Davidson, J., and De Silva, S. 2000. Composite volcanoes. Academic Press, San Diego, Calif.

Dóniz, J., Romero, C., Coello, E., Guillèmn, C., Sánchez, N., GarcíaCacho, L., and García, A. 2008. Morphological and statistical characterisation of recent mafic volcanism on Tenerife (Canary Islands, Spain). 
Journal of Volcanology and Geothermal Research, Vol. 173, pp. 185-195. doi:10.1016/j.jvolgeores.2007.12.046.

Eckert, S., Kellenberger, T., and Itten, K. 2005. Accuracy assessment of automatically derived digital elevation models from ASTER data in mountainous terrain. International Journal of Remote Sensing, Vol. 26, pp. 1943-1957. doi:10.1080/0143116042000298306.

Farr, T.G., Rosen, P.A., Caro, E., Crippen, R., Duren, R., Hensley, S., Kobrick, M., Paller, M., Rodriguez, E., Roth, L., Seal, D., Shaffer, S., Shimada, J., Umland, J., Werner, M., Oskin, M., Burbank, D., and Alsdorf, D. 2007. The Shuttle Radar Topography Mission. Reviews of Geophysics, Vol. 445.

Favalli, M., Karátson, D., Mazzarini, F., Pareschi, M.T., and Boschi, E. 2009. Morphometry of scoria cones located on a volcano flank: A case study from Mt. Etna (Italy), based on high-resolution LiDAR data. Journal of Volcanology and Geothermal Research, Vol. 186, pp. 320-330. doi:10.1016/j.jvolgeores.2009.07.011.

Fedotov, S.A., Balesta, S.T., Dvigalo, V.N., Razina, A.A., Flerov, G.B., and Chirkov, A.M. 1984. New Tolbachik volcanoes. In Great Tolbachik fissure eruption, Kamchatka 1975-1976. Edited by S.A. Fedotov. Nauka, Moscow, Russia. pp. 214-279.

Fernández, J., Romero, R., Carrasco, D., Luzón, F., and Araña, V. 2002. InSAR volcano and seismic monitoring in Spain. Results for the period 1992-2000 and possible interpretations. Optics and Lasers in Engineering, Vol. 37, No. 2-3, pp. 285-297.

Furuya, M. 2007. Application of interferometric point target analysis to IzuOshima volcano. In Proceedings of the Envisat Symposium 2007, 23-27 April 2007, Montreux, Switzerland. Edited by H. Lacoste and L. Ouwehand. European Space Agency (ESA) Publications Division, Noordwijk, The Netherlands. ESA SP-636. Available from earth.esa.int/workshops/ envisatsymposium/proceedings/sessions/4B4/462406fu. pdf [accessed 20 September 2009]

Ge, L., Ng, A.H.-M., Wang, H., and Rizos, C. 2009. Crustal deformation in Australia measured by satellite radar interferometry using ALOS/PALSAR imagery. Journal of Applied Geodesy, Vol. 3, No. 1, pp. 47-53. doi:10.1515/ JAG.2009.005.

Gesch, D.B., Muler, J.-P. and Farr, T.G. 2006. The Shuttle Radar Topography Mission - Data validation and applications (Foreword). Photogrammetric Engineering \& Remote Sensing, Vol. 72, No. 3, pp. 233-235.

Goncalves, J.A., and Oliveira, A.M. 2004. Accuracy analysis of DEMs derived from ASTER imagery. International Archives of Photogrammetry and Remote Sensing, Vol. 35, pp. 168-172.

Guth, P.L. 2006. Geomorphometry from SRTM: Comparison to NED. Photogrammetric Engineering \& Remote Sensing, Vol. 72, No. 3, pp. 269-277.

Hasenaka, T., and Carmichael, I.S.E. 1985. A compilation of location, size, and geomorphological parameters of volcanoes of the MichoacanGuanajuato volcanic field, central Mexico. Geofisica Internacional, Vol. 24, pp. 577-607.

Hirano, A., Welch, R., and Lang, H. 2003. Mapping from ASTER stereo image data: DEM validation and accuracy assessment. ISPRS Journal of Photogrammetry and Remote Sensing, Vol. 57, No. 5-6, pp. 356-370. doi:10. 1016/S0924-2716(02)00164-8.

Hooper, D.M. 1995. Computer-simulation models of scoria cone degradation in the Colima and Michoacan-Guanajuato volcanic fields, Mexico. Geofisica Internacional, Vol. 34, No. 3, pp. 321-340.

Hooper, D.M., and Sheridan, M. 1998. Computer-simulation models of scoria cone degradation. Journal of Volcanology and Geothermal Research, Vol. 83, pp. 241-267. doi:10.1016/S0377-0273(98)00031-6.
Hu, Z., Ge, L., Li, X., Zhang, K., Ng, A.H.-M., and Rizos, C. 2009. ALOS PALSAR observation of Kilauea Volcano activities from 2006 to 2007. In Proceedings of the International Conference on Geo-spatial Solutions for Emergency Management \& 50th Anniversary of the Founding of the Chinese Academy of Surveying \& Mapping, 14-16 September 2009, Beijing, China. pp. 47-52. Available from www.gmat.unsw.edu.au/snap/publications/huz_etal2009a.pdf [accessed 20 September 2009].

Huggel, C., Schneider, D., Miranda, P.J., Delgado Granados, H., and Kääb, A. 2008. Evaluation of ASTER and SRTM DEM data for lahar modeling: A case study on lahars from Popocatépetl Volcano, Mexico. Journal of Volcanology and Geothermal Research, Vol. 170, pp. 99-110. doi:10. 1016/j.jvolgeores.2007.09.005.

Inbar, M., and Risso, C. 2001. A morphological and morphometric analysis of a high density cinder cone volcanic field - Payun Matru, south-central Andes, Argentina. Zeitschrift fuer Geomorphologie, Vol. 45, No. 3, pp. 321-343.

Jonsson, S., Zebker, H.A., Cervelli, P., Segall, P., Carbeil, H., MouginisMark, P., and Rowland, S. 1999. A shallow-dipping dike fed the 1995 flank eruption at Fernandina Volcano, Galapagos: observed by satellite radar interferometry. Geophysical Research Letters, Vol. 26, pp. 10771080. doi:10.1029/1999GL900108.

Joyce, K.E., Samsonov, S., Manville, V., Jongens, R., Graettinger, A., and Cronin, S.J. 2009. Remote sensing data types and techniques for lahar path detection: A case study at Mt. Ruapehu, New Zealand. Remote Sensing of Environment, Vol. 113, pp. 1778-1786. doi:10.1016/j.rse.2009.04.001.

Kääb, A. 2005. Combination of SRTM3 and repeat ASTER data for deriving alpine glacier flow velocities in the Bhutan Himalaya. Remote Sensing of Environment, Vol. 94, No. 4, pp. 463-474. doi:10.1016/j.rse.2004.11.003.

Kamp, U., Bolch, T., and Olsenholler, J. 2003. DEM generation from ASTER satellite data for geomorphometric analysis of Cerro Sillajhuay Chile/Bolivia. In Proceedings of the ASPRS 2003 Annual Conference, Anchorage, Alaska, American Society for Photogrammetry and Remote Sensing (ASPRS), Bethesda, Md.

Kervyn, M., Kervyn, F., Goossens, R., Rowland, S.K., and Ernst, G.G.J. 2007. Mapping volcanic terrain using high-resolution and 3D satellite remote sensing. In Mapping hazardous terrain using remote sensing. Edited by R.M. Teeuw. Geological Society of London, London, U.K., Special Publication 283. pp. 5-30.

Kervyn, M., Ernst, G.G.J., Goossens, R., and Jacobs, P. 2008. Mapping volcano topography with remote sensing: ASTER vs. SRTM. International Journal of Remote Sensing, Vol. 29, No. 22, pp. 6515-6538.

Lagios, E., Sakkas, V., Parcharidis, I., and Dietrich, V. 2005. Ground deformation of Nisyros Volcano (Greece) for the period 1995-2002: results from DinSAR and DGPS observation. Bulletin of Volcanology, Vol. 68, No. 2, pp. 201-214. doi:10.1007/s00445-005-0004-y.

Massonnet, D., Rossi, M., Carmona, C., Adragna, F., Peltzer, G., Fiegl, K., and Rabaute, T. 1993. The displacement field of the Landers earthquake mapped by radar interferometry. Nature (London), Vol. 364, pp. 138142. doi:10.1038/364138a0

Massonnet, D., Briole, P., and Arnaud, A. 1995. Deflation of Mount Etna monitored by spaceborne radar interferometry. Nature (London), Vol. 375, pp. 567-570. doi:10.1038/375567a0.

Matsuoka, M. 2006. Use of ALOS/PALSAR imagery for monitoring areas damaged due to recent natural disasters. In Disaster Forewarning Diagnostic Methods and Management, Special JAXA Session, 13-17 November 2006, Goa, India. Edited by F. Kogan, S. Habib, V.S. Hegde, and M. Matsuoka. Proceedings of SPIE Volume 6412, The International Society for Optical Engineering, Bellingham, Wash. pp. 6412-04-6412-07. 
Mouginis-Mark, P.J., Rowland, S.K., and Garbeil, H. 1996. Slopes of western Galapagos volcanoes from airborne interferometric radar. Geophysical Research Letters, Vol. 23, pp. 3767-3770. doi:10.1029/ 96GL03280.

Nikolakopoulos, K.G., Kamaratakis, E.K., and Chrysoulakis, N. 2006. SRTM vs ASTER elevation products: Comparison for two regions in Crete, Greece. International Journal of Remote Sensing, Vol. 27, No. 21, pp. 4819-4838. doi:10.1080/01431160600835853.

Parrot, J.F. 2007. Tri-dimensional parameterization: an automated treatment to study the evolution of volcanic cones. Geomorphologie, Vol. 3, pp. 247-258.

Pelletier, J.D., and Cline, M.L. 2007. Nonlinear slope-dependent sediment transport in cinder cone evolution. Geology, Vol. 35, No. 12, pp. 10671070. doi:10.1130/G23992A.1.

Pieri, D., and Abrams, M. 2004. ASTER watches the world's volcanoes: a new paradigm for volcanological observations from orbit. Journal of Volcanology and Geothermal Research, Vol. 135, pp. 13-28. doi:10.1016/j. jvolgeores.2003.12.018.

Porter, S.C. 1972. Distribution, morphology, and size frequency of cinder cones on Mauna Kea Volcano, Hawaii. Geological Society of America Bulletin, Vol. 83, pp. 3607-3612. doi:10.1130/0016-7606(1972)83[3607:DMASFO]2. $0 . \mathrm{CO} ; 2$.

Rodríguez, E., Morris, C.S., and Belz, J.E. 2006. A global assessment of the SRTM performance. Photogrammetric Engineering \& Remote Sensing, Vol. 72, No. 3, pp. 249-260.

Sandwell, D.T., Sichoix, L., Agnew, D., Bock, Y., and Minster, J.-B. 2000. Near realtime radar interferometry of the Mw 7.1 Hector Mine Earthquake. Geophysical Research Letters, Vol. 27, pp. 3101-3104. doi:10. 1029/1999GL011209.
Settle, M. 1979. The structure and emplacement of cinder cone fields. American Journal of Science, Vol. 279, pp. 1089-1107. doi:10.2475/ajs.279.10.1089.

Stevens, N.F., Garbeil, H., and Mouginis-Mark, P.J. 2004. NASA EOS Terra ASTER: Volcanic topographic mapping and capability. Remote Sensing of Environment, Vol. 90, pp. 405-414. doi:10.1016/j.rse. 2004.01.012.

Thapa, K., and Bossler, J. 1992. Review article: Accuracy of spatial data used in Geographic Information Systems. Photogrammetric Engineering \& Remote Sensing, Vol. 58, pp. 835-841.

Wiart, P.A.M., Oppenheimer, C., and Francis, P. 2000. Eruptive history of Dubbi volcano, northeast Afar (Eritrea), revealed by optical and SAR image interpretation. International Journal of Remote Sensing, Vol. 21, No. 5, pp. 911-936. doi:10.1080/014311600210353.

Wood, C.A. 1980a. Morphometric evolution of cinder cones. Journal of Volcanology and Geothermal Research, Vol. 7, pp. 387-413. doi:10. 1016/0377-0273(80)90040-2.

Wood, C.A. 1980b. Morphometric analysis of cinder cone degradation. Journal of Volcanology and Geothermal Research, Vol. 8, pp. 137-160. doi:10.1016/0377-0273(80)90101-8.

Wright, R., Garbeil, H., Baloga, S.M., and Mouginis-Mark, P.J. 2006. An assessment of shuttle radar topography mission digital elevation data for studies of volcano morphology. Remote Sensing of Environment, Vol. 105, pp. 41-53. doi:10.1016/j.rse.2006.06.002.

Yu, J.H., Ge, L., and Rizos, C. 2009. Digital elevation model generation from interferometric synthetic aperture radar using multi-scale method. In Proceedings of the Surveying \& Spatial Sciences Institute Biennial International Conference, 28 September - 2 October 2009, Adelaide, Australia. Surveying and Spatial Sciences Institute (SSSI), Victoria, Australia. 